Closely related to the debate over NSF's coordinating and evaluative role was the question of whether the Foundation should be a "gap filler", whether it should strategically identify and stimulate lagging fields under-supported by missionorientated agencies, or whether it should become the principal or even the sole patron of basic science throughout the entire federal government. Waterman's position was again one of moderation. $\mathrm{He}$ agreed that NSF had a responsibility to ensure the "balanced" development of science as a whole, but refused to confine NSF purely to gap-filling, feeling that it should have a presence in all principal areas of the natural sciences. At the same time, he was diffident about taking over programmes in basic research from other agencies as he was being urged to do by the Bureau of the Budget. This intermediate position between gap-filler and principal patron of basic science is one that has persisted to this day.

Many of the issues and debates described by Dr England persist to this day. They are the perennials of science policy - geographical distribution and institutional development versus the support of excellence; federal support of the basic social sciences; the project grant system with peer review versus other modes of support; the determination of priorities; the proper balance between big science and little science; and payment of institutional costs such as faculty salaries and overhead costs from research grants. Other issues which loom large in this history have mercifully disappeared - loyalty oaths or loyalty investigations for fellowship recipients or grant recipients; the desirability of fostering international scientific communication; the role of NSF in defenceorientated research; presidential appointment of the Director; and patent policy.

For those of us who lived through the history of the NSF and the numerous science policy debates of the past 30 years, this book is a sentimental journey. It is a remarkable story, particularly so in the general context of the American political system. The book will remain an indispensible source book for future historians and analysts of American science policy. One can also not fail to be impressed that so many contemporary debates are not new, but have a venerable history.

Readers will look forward with great eagerness to the planned future volumes in this series, which will carry the story up to date. Yet I believe this volume will remain the most interesting simply because it contains the roots of the later events and developments, which were mostly elaborations and refinements on trends that were already apparent in the Foundation's early history.

Harvey Brooks is Benjamin Pierce Professor of Technology and Public Policy at Harvard University. He was a member of the President's Science Advisory Committee from 1959 to 1964.

\section{All in theory - the analysis of music}

\section{Christopher Longuet-Higgins}

A Generative Theory of Tonal Music.

By Fred Lerdahl and Ray Jackendoff. MIT Press: 1983. Pp.368. \$35, £31.50.

FCR SCME time it has been rumoured in music-theoretical circles that a definitive theory of music had at last been formulated by the Chomskyan linguist Ray Jackendoff and the composer Fred Lerdahl. Their book would redefine the field of music theory, and make all previous work seem as antediluvian as pre-Chomskyan linguistics after the publication of Syntactic Structures. Now, at long last, $A$ Generative Theory of Tonal Music emerges from the MIT Press, adorned with wide margins and expensively engraved musical illustrations from the works of the very best classical composers. The authors, so the flyleaf announces, "collaborate here on a seminal theory synthesizing the outlook and methodology of contemporary linguistics with the insights of recent music theory".

It would be impossible to gainsay the worth of such a project, but like so many books on musical theory this one woefully disappoints the expectant reader. It adopts the methodology of contemporary linguistics only in so far as the earliest and latest chapters (due largely, one suspects, to Jackendoff) belabour the reader with principles of theory construction and claims to generality which are quite unjustified by the detailed contents of the central chapters. "Recent music theory" apparently comprises a series of "preference rules" of almost unbelievable vagueness for reducing a piece of homophonic music - or rather, its printed score - to a single tonic chord, in the manner of the early twentiethcentury theorist Heinrich Schenker.

The only sense in which the theory might be described as "generative" is that it permits the analyst to crect above the notes of a musical score a flimsy tree of dependency relations, but the authors appear not to notice the connection between their ideas and those of dependency grammar. They are uncomfortably aware of the formal imprecision of their preference rules, but they elevate into a positive virtue the evident impossibility of incorporating them into effective procedures for the structural description of "musical surfaces" - a term which they use freely but without formal definition (it does not even appear in the index). As for the word "tonal" in the title, the book is utterly barren of any new ideas on tonality; as the authors say on page 117:

In what follows we can take as given the classical Western tonal pitch system - the major-minor scale system, the traditional classifications of consonance and dissonance, the triadic harmonic system with its roots and inversions, the circle-of-fifths system, and the principles of good voicc-lcading. Though all of these principles could and should be formalized, they are largely idiom-specific, and are well understood informally within the traditional disciplines of harmony and counterpoint. Nothing will be lost if we conveniently consider them to be an input to the theory of reductions.

It does not seem to occur to them that an elementary obligation on any theory of tonal music (in the sense in which they use that term) is to examine whether the principles they mention are indeed as well understood as they claim, or whether some of these principles (such as the circle-offifths system) actually do violence to the conceptual basis of tonality. If, furthermore, the tonal principles to which the authors appeal in their theory of reductions are indeed so idiom-specific, how can one be sure that the theory has any application outside the Western tonal tradition?

The detailed discussions of "group structure" and "metrical structure", and the related processes of "time-span reduction" and "prolongational reduction" are unsatisfactory in a different way; not only does the latter process look uncomfortably like a remedy for the deficiencies of the former, but it could not even in principle be applied to contrapuntal music such as fugue. Moreover, the relevant parts of the theory do not seem to accommodate in any natural way such important concepts as rhythmic ambiguity or syncopation; for the concept of syncopation, this is the best they can supply in the way of a formal definition (p.77):

In general the phenomenon of syncopation can be formally [sic] characterized as a situation [sic] in which the global demands of metrical wellformedness conflict with and override local preferences.

Lerdahl and Jackendoff are, it seems, in favour of constructing a formally precise theory of music, in principle but not in practice. In point of fact much of the necessary groundwork has been done by other theorists in recent years, particularly. in England; but of this work the authors scem to be quite unawarc, although it would enable them to clarify their own thoughts considerably. One cannot help feeling that in view of the very limited range of application of their present ideas it would have been better to make more modest claims for what they have so far achieved.

In spite of all its faults, however, the book will undoubtedly provoke thought, especially among psychologists of music, as to what a theory of tonal music would look like if somebody were actually to producc one.

Christopher Longuet-Higgins is Royal Society Research Professor in the Centre for Research on Perception and Cognition, University of Sussex. 